
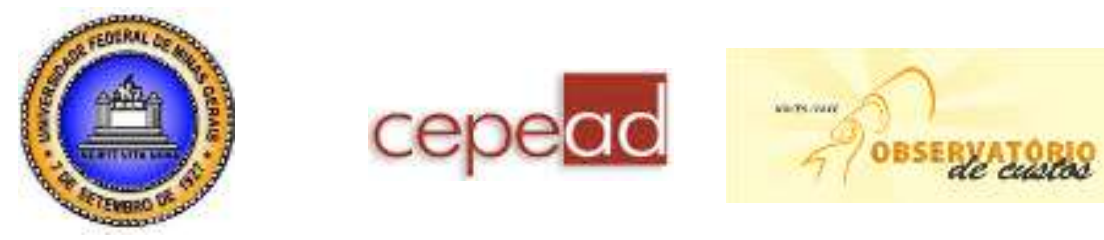

\title{
GESTÃO DE RESÍDUOS DE SERVIÇO DE SAÚDE EM ORGANIZAÇÃO MILITAR: UM ESTUDO DE CASO NA MARINHA DO BRASIL
}

\section{WASTE MANAGEMENT OF HEALTH CARE IN MILITARY ORGANIZATION: A CASE STUDY IN THE NAVY OF BRAZIL}

\section{GESTIÓN DE RESIDUOS DE LA SALUD EN ORGANIZACIÓN MILITAR: UN ESTUDIO DE CASO EN LA ARMADA DE BRASIL}

Romero Albuquerque Maranhão

UNINOVE

ram060973@gmail.com

\author{
Maria Tereza Saraiva Souza \\ UNIFEI \\ mariaterezasaraivas@gmail.com \\ Claudia Echevenguá Teixeira \\ UNINOVE \\ ceteixeira10@gmail.com
}

Submetido em: 04/02/2014

Artigo aceito em: 10/10/2014

\section{Resumo}

O objetivo do estudo consiste em analisar a gestão de resíduos de serviços de saúde em uma Organização Militar da Marinha do Brasil. Os resultados mostram que a gestão de resíduos sólidos na área de saúde está sendo aplicada no Posto Médico da Esquadra. O Plano de Gerenciamento de Resíduos implantado na Organização militar evita problemas ambientais e atende as exigências legais, pois gera aumento no tempo de vida útil dos aterros sanitários, em função da correta separação e destinação final dos resíduos gerados, bem como benefícios ambientais à sociedade.

Palavras-chave: Gestão de Resíduos. Posto Médico. Organização Militar.

\section{Abstract}

The objective of the study is to analyze waste management of health services in a Military Organization of the Navy of Brazil. The results show that the solid waste management in healthcare is being applied in the Navy Medical Centre. The Waste Management Plan implemented in Military Organization avoids environmental problems and meets the legal requirements, it generates an increase in the lifespan of landfills, according to the proper separation and disposal of waste generated as well as environmental benefits to society.

Keywords: Waste Management. Medical Post. Military organization.

\section{Resumen}

El objetivo del estudio es analizar la gestión de residuos de servicios de salud en una Organización Militar de la Marina de Brasil. Los resultados muestran que la gestión de residuos sólidos en la asistencia sanitaria se aplica en el Centro Médico Naval. El Plan de Gestión de Residuos implementado en Organización Militar evita los problemas medioambientales y cumple con los requisitos legales, que genera un aumento en la vida útil 

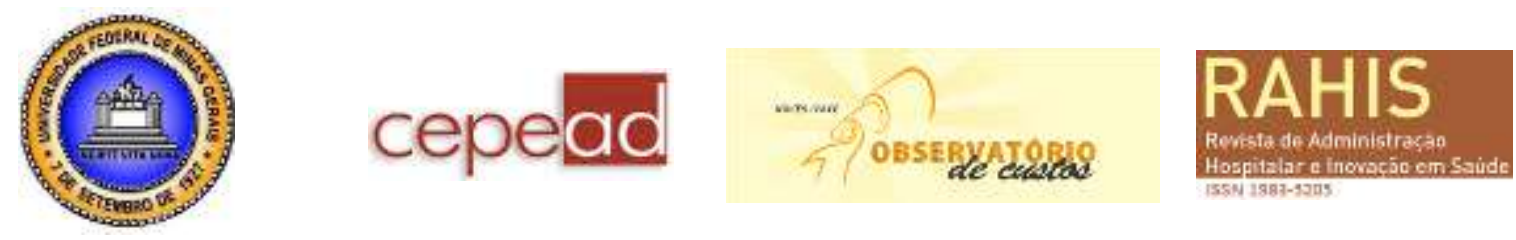

de los rellenos sanitarios, de acuerdo con la separación y disposición adecuada de los residuos generados, así como los beneficios ambientales a la sociedad.

Palabras clave: Gestión de residuos. Clínica. Organización militar.

\section{INTRODUÇÃO}

A busca de uma solução adequada para a destinação correta dos Resíduos de Serviços de Saúde (RSS) constitui uma medida importante para o dia a dia de uma unidade hospitalar. Essa iniciativa contribuiu para manter a saúde pública, recuperar o ambiente e beneficiar a qualidade de vida dentro e fora dos hospitais (SISINNO e MOREIRA, 2005; VIRIATO e MOURA, 2011).

Conforme Silva \& Hoppe (2005) os RSS são gerados por prestadores de assistência médica, odontológica, laboratorial, farmacêutica e instituições de ensino e pesquisas na área de medicina relacionadas tanto à população humana quanto à veterinária. De acordo com Castro (2003), os serviços de assistência médica são um dos grandes geradores de resíduos perigosos, com práticas que colocam em risco o meio ambiente, apesar de imprescindíveis ao desenvolvimento humano (FERREIRA, 1995; CALEGARE et al., 2005).

Os RSS, apesar de representarem uma pequena parcela em relação ao total de resíduos gerados em uma comunidade, são fontes potenciais de contaminação ao meio ambiente e apresentam um risco adicional aos trabalhadores dos serviços de saúde e a comunidade em geral, quando gerenciados de forma inadequada (SILVA e HOPPE, 2005; ALI e KUROIWA, 2009).

Alguns resíduos, como por exemplo, peças anatomo-patológicas, agulhas e seringas, bandagens, roupas descartáveis, gazes, entre outros, podem conter microrganismos patogênicos com capacidade de disseminação de doenças infectocontagiosas, devido à relação direta destes com o atendimento de pacientes. Além disso, alguns constituintes apresentam características de toxicidade, inflamabilidade, corrosividade e reatividade no caso de ácidos, remédios fora da validade, além de outros resíduos (ALI e KUROIWA, 2009; CAMARGO et al., 2009).

O êxito no manejo adequado em uma instituição de saúde ultrapassa os seus limites, beneficiando a comunidade local e o entorno. Em diversos estabelecimentos de saúde, a baixa eficiência no gerenciamento dos RSS, em especial na etapa de segregação, é decorrente do acondicionamento dos resíduos comuns juntamente com o biológico-infectante (ALI e KUROIWA, 2009; VIRIATO e MOURA, 2011). Viriato e Moura (2011), ainda, mencionam que a composição gravimétrica dos resíduos de serviços de saúde monstra uma semelhança com os resíduos sólidos domésticos. Componentes como papel, papelão, plásticos e vidros aparecem em percentuais elevados em diversos estudos realizados.

Schneider (2004) desenvolveu um estudo comparativo entre um sistema de gerenciamento de RSS de um hospital público e de um privado. No estudo foi obtido uma geração de 3,5 kg/leito.dia de RSS para o hospital privado e 2,6 kg/leito.dia de RSS para o hospital público. Dentre estes cerca de $1,3 \mathrm{~kg} / \mathrm{leito}$ dia representam a geração de resíduos biológico infectante para o hospital privado e cerca de $1,1 \mathrm{~kg} /$ leito.dia para o hospital público. Após dois anos, por meio de um processo de monitoramento e de educação continuada, foi possível reduzir nos hospitais cerca de $30 \%$ da geração de resíduos infectantes. A autora destacou a importância positiva dos programas educacionais e os sistemas organizacionais para uma melhoria das práticas de segregação. 

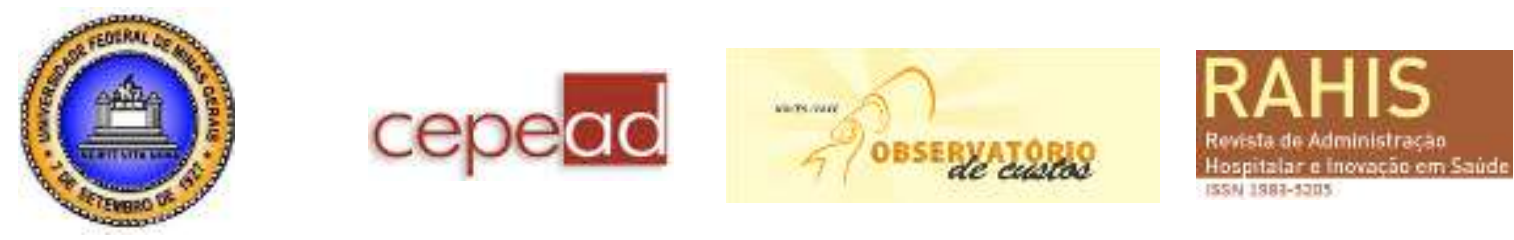

$\mathrm{Na}$ área da saúde, o fator humano é um dos grandes desafios para a implementação de programas de gestão de RSS. Isso se deve ao fato de que tanto os funcionários dos setores técnicos (ambulatório, emergência, cirurgia, raio X, UTI, entre outros) como os de infraestrutura (secretaria, almoxarifado, compras, cozinha etc.), em todos os níveis hierárquicos, deverão estar atentos aos procedimentos relativos ao controle de desperdícios. Mas, fatores como o trabalho em turnos, a diferença entre níveis de escolaridade e níveis socioeconômicos e as diferenças entre os graus de envolvimento com a empresa, além da sobrecarga e do estresse decorrentes desse tipo de trabalho podem comprometer a conscientização e o treinamento dos funcionários (MACEDO et al., 2007) . Por conseguinte, dificulta a padronização homogênea, verticalizada e extensa dos procedimentos e das atitudes pessoais que ajudarão na redução dos desperdícios (SISINNO \& MOREIRA, 2005).

No Brasil a gestão dos RSS teve como marco a Resolução n .5 do CONAMA de 1993 (BRASIL, 1993), sendo atribuídas responsabilidades específicas aos vários segmentos envolvidos como: geradores, autoridades sanitárias e ambientais. Entretanto a Resolução CONAMA $n^{\circ}$. 358/2005 (BRASIL, 2005) complementa os procedimentos do gerenciamento, estabelecendo as diretrizes para o tratamento e disposição dos RSS Já a Resolução da Diretoria Colegiada (RDC) ANVISA $n^{\circ}$. 306/2004 (BRASIL, 2004) dissemina o Regulamento Técnico para o gerenciamento dos RSS e, recentemente, a Lei $\mathrm{n}^{\circ}$. 12.305, de agosto de 2010, institui a Política Nacional de Resíduos Sólidos (PNRS) (BRASIL, 2010) estabelece em seu art. $20^{\circ}$ procedimentos de elaboração de planos de gerenciamento de resíduos de diferentes origens, incluindo aqueles gerados em serviços de saúde. Importante ressaltar que por esta política e outros autores (TCHOBANOGLOUS et al., 1993), o gerenciamento de resíduos envolve um conjunto de ações exercidas, direta ou indiretamente, nas etapas de coleta, transporte, transbordo, tratamento e destinação final ambientalmente adequada, de acordo com plano municipal de gestão integrada de resíduos sólidos ou com plano de gerenciamento de resíduos sólidos.

A Resolução CONAMA n 358/2005 (BRASIL, 2005) trata do gerenciamento sob o prisma da preservação dos recursos naturais e do meio ambiente e define a competência aos órgãos ambientais estaduais e municipais para estabelecerem critérios para o licenciamento ambiental dos sistemas de tratamento e destinação final dos RSS. Além disso, preconiza que os resíduos infectantes devem ser submetidos a processos de tratamento que promovam redução de carga microbiana, antes de serem encaminhados para aterro sanitário. Bem como, menciona que a redução na fonte (reduzir ou evitar a produção de resíduos) poderá aumentar a eficiência dos equipamentos e dos processos.

Enquanto, a RDC $n^{\circ} 306 / 2004$ (BRASIL, 2004) concentra sua regulação no controle dos processos de segregação, acondicionamento, armazenamento, transporte, tratamento e disposição final. Estabelece procedimentos operacionais em função dos riscos envolvidos e concentra seu controle na inspeção dos serviços de saúde.

A PNRS preconiza no art. $1^{\circ}$ (BRASIL, 2010) que estão sujeitas à observância da lei as "pessoas físicas ou jurídicas, de direito público ou privado, responsáveis, direta ou indiretamente, pela geração de resíduos sólidos e as que desenvolvam ações relacionadas à gestão integrada ou ao gerenciamento de resíduos sólidos".

Corrêa (2003) ressaltar que, com base na legislação vigente, a responsabilidade pelo gerenciamento dos resíduos é do agente gerador. Neste contexto, se enquadram as Organizações Militares da Marinha do Brasil, que em virtude das atividades de saúde por elas prestadas, quer seja nas atividades ambulatorial e hospitalar das Organizações Militares de Saúde, quer seja na rotina de atendimento das Seções de Saúde, tornam-se elementos 

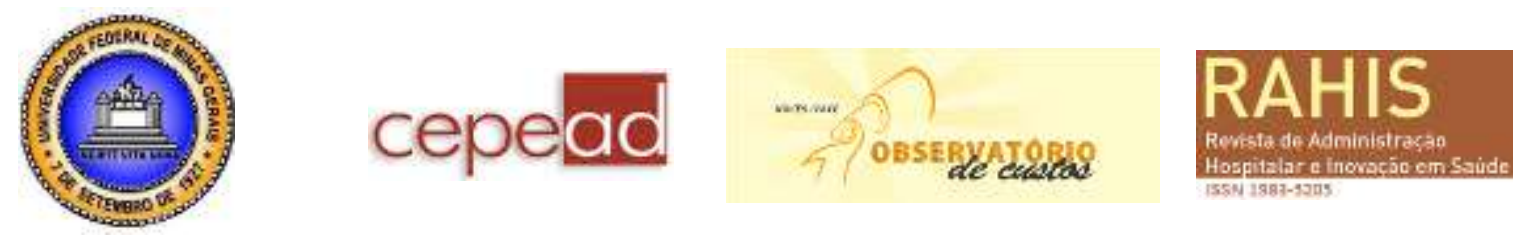

geradores de resíduos dos serviços de saúde. Assim, os Diretores e Comandantes das diversas Organizações Militares, adquirem responsabilidade perante o Ministério Público.

$\mathrm{Na}$ Marinha existem hospitais de grande e médio porte, policlínicas, odontoclínicas postos médicos e ambulatórios distribuídos em diversos Estados que prestam assistência aos militares e seus dependentes.

O presente artigo analisa a gestão de resíduos de serviços de saúde em uma Organização Militar da Marinha do Brasil. A unidade de análise do estudo de caso foi o Posto Médico da Esquadra, localizado na Base Naval do Rio de Janeiro. O estudo justifica-se, pela verificação da apropriada implementação de um plano que evita problemas ambientais e atende a exigências legais. A implantação do Plano de Gerenciamento de RSS gera aumento no tempo de vida útil dos aterros sanitários, em função da correta separação e destinação final dos resíduos sólidos gerados, bem como benefícios ambientais à sociedade.

\section{REVISÃO BIBLIOGRÁFICA}

A questão da redução da geração dos resíduos sólidos é atualmente um dos maiores desafios tanto para o setor público como privado de fornecimento de bens e serviços. A partir da publicação da Política Nacional de Resíduos Sólidos, esse desafio tornou-se uma necessidade premente uma vez que metas de redução - com vistas a diminuir a quantidade de resíduos encaminhados para disposição final - passou a ser demandada para todas as esferas (SISINNO et al., 2011), e estas ações preconizadas em seus planos de gerenciamento.

Neste contexto, a adoção de abortagens e métodos dentro do conceito de ecoeficiência aparecem como ferramentas capazes de auxiliar na não geração/redução da geração, identificando os aspectos econômicos e ambientais relativos à produção de resíduos sólidos (SISINNO et al., 2011).

Para Sisinno e Barros (2004), as empresas ecoeficientes obtêm benefícios econômicos - rapidez em seus processos e qualidade de seus produtos, com redução nos custos associados aos desperdícios de água, energia e materiais - ao mesmo tempo em que alcançam benefícios ambientais por meio da redução progressiva da geração de resíduos sólidos, efluentes líquidos e emissões atmosféricas, inserindo em seu processo gerencial o conceito de prevenção da poluição e de riscos ocupacionais.

De acordo com Sisinno e Moreira (2005), a visão moderna da tentativa de eliminação ou pelo menos de redução na geração de resíduos e efluentes tem sido uma preocupação constante das organizações situadas em países desenvolvidos. A gestão dos resíduos gerados pela organização durante o processamento de seus produtos e serviços representa a forma direta de resgatar a harmonia entre os elementos do meio ambiente e, por esse motivo, pode aumentar a ecoeficiência do negócio (DEMAJOROVIC, 2006; BARBIERI, 2007; VELLANI e RIBEIRO, 2009).

A adequada e correta classificação desses resíduos permite um manuseio eficiente, econômico e seguro, além de facilitar a futura segregação, reduzindo riscos sanitários e o gasto com o seu manejo (VIRIATO e MOURA, 2011).

Viriato e Moura (2011) ressaltam que em uma instituição de saúde a gestão adequada dos RSS ultrapassa os seus limites, beneficiando a comunidade local e o entorno. Em vários estabelecimentos de saúde, a baixa eficiência no gerenciamento dos RSS pode acarretar diversos problemas de ordem econômica, social e ambiental. 

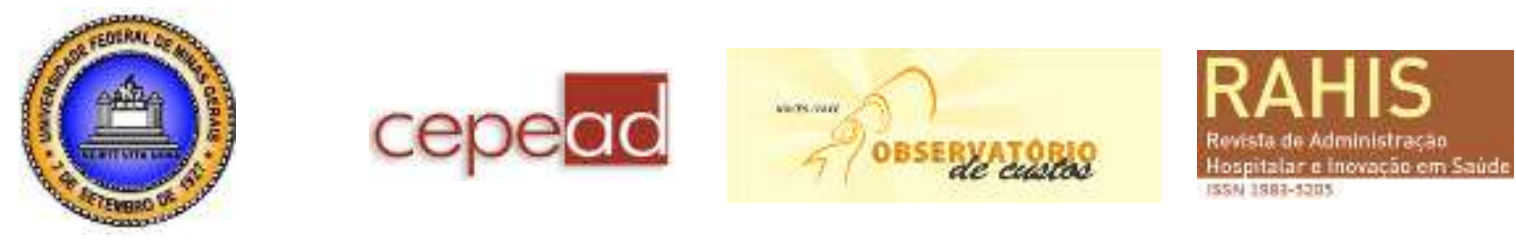

De acordo com Hossain et al. (2011) a gestão de RSS continua a ser um grande desafio, particularmente, na maioria das instalações de saúde dos países em desenvolvimento. Inúmeras pesquisas têm sido realizadas sobre a gestão de resíduos de saúde.

A destinação final inadequada dos resíduos, bem como o manuseio impróprio e o descarte indevido tem aumentado significativamente os riscos à saúde e poluição ambiental devido à natureza infecciosa dos resíduos. Embora, haja iniciativas significativas em relação à manipulação e destinação final dos resíduos de saúde, na prática a gestão é insatisfatória, ficando evidente a partir da coleta inicial até a disposição final. Na maioria dos casos, os principais motivos para uma gestão insatisfatória são a falta de legislação adequada, a falta de funcionários especializados, falta de consciência e controle efetivo. Além disso, a maioria dos centros de saúde em países em desenvolvimento têm enfrentado dificuldades financeiras e, portanto, à procura de métodos eficientes de eliminação de resíduos hospitalares (TAGHIPOUR e MOSAFERI, 2009a; HOSSAIN et al., 2011).

Para Ananth et al. (2010), que avaliaram 12 países asiáticos, os riscos dos resíduos associados com a saúde e sua gestão ganharam a atenção de todo o mundo em vários eventos, fóruns locais e internacionais. No entanto, a necessidade de gestão adequada dos resíduos de saúde vem ganhando reconhecimento lentamente devido aos problemas associados com as práticas inapropriadas, incluindo a exposição a agentes infecciosos e substâncias tóxicas.

Apesar da magnitude do problema, práticas, capacidades e políticas em muitos países em lidar com a destinação final dos resíduos de saúde, especialmente as nações em desenvolvimento, é inadequada e requer intensificação e providências urgentes (ANANTH $e t$ al., 2010). Corrobora tal entendimento os estudos realizados por Taghipour e Mosaferi (2009a) no Irã, Ndidi et al. (2009) na Nigéria e Ali et al. (2009) no Paquistão, na Tailândia e na Mongólia.

Mohamed et al. (2009) avaliando a questão no Bahrein registram que os problemas de má gestão (segregação, manuseio, transporte e destinação final) são identificados em instituições públicas e privadas de saúde. Taghipour e Mosaferi (2009a), também, evidenciam os mesmos problemas nos hospitais iranianos.

Além disso, Uysal e Tinmaz (2004), estudando hospitais da Turquia, registraram que os resíduos não recebem a devida atenção por parte do poder público e são eliminados junto com o lixo municipal e industrial.

Para Abd El-Salam (2010), que estudou as características físico-químicas dos resíduos hospitalares no Egito, identificou que quase dois terços dos resíduos de saúde são semelhantes aos resíduos domésticos. Taghipour e Mosaferi (2009b) constataram que aproximadamente $70 \%$ dos resíduos provenientes das instituições de saúde (públicas, privadas e militares) no Irã são considerados resíduos domésticos, enquanto $30 \%$ dos resíduos são considerados infecciosos.

Outrossim, Abd El-Salam (2010), constatou também que a segregação dos resíduos de saúde não obdece procedimentos ou padrões, sendo descartados como lixo doméstico. Observou, ainda, que os resíduos líquidos são encaminhados para o sistema municipal de esgoto sem tratamento prévio, tal fato corrobora com a pesquisa realizada por Uysal \& Tinmaz (2004). Abdulla et al. (2008) mencionam que 57\% dos hospitais pesquisados na Jordânia também descartam os resíduos líquidos diretamente na rede de esgoto do município.

Taghipour e Mosaferi (2009a) registram que não existem instruções práticas, ou de supervisão adequada sobre os diferentes níveis de gestão de resíduos nos hospitais do Irã. Todavia, registram que em quase todos os hospitais há um gestor para a Gestão de Resíduos, porém o programa de treinamento de pessoal não é eficiente. Ressaltam, também, que não são 

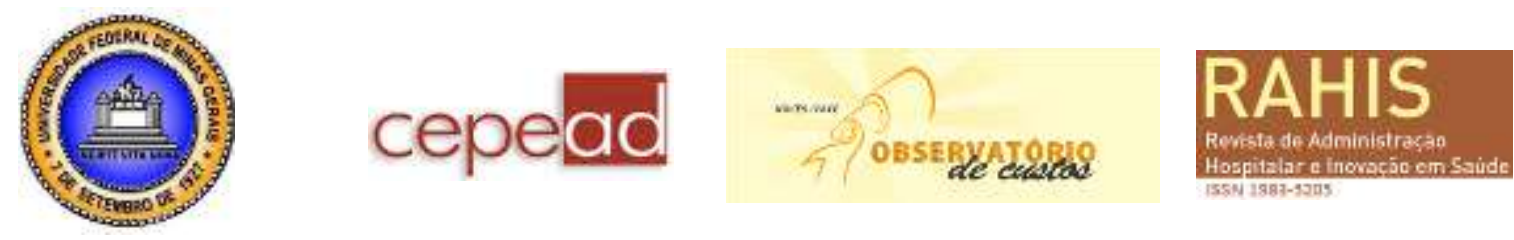

satisfatórias as condições de armazenamento temporário dos resíduos, nem os equipamentos de proteção para o pessoal envolvido no manuseio e transporte do material.

\section{MÉTODOS DA PESQUISA}

Essa pesquisa exploratória foi desenvolvida por intermédio da abordagem de estudo de caso único. Esse tipo de pesquisa facilita a compreensão do fenômeno investigado, pela natureza e magnitude do fenômeno (YIN, 2005).

Dada à natureza heterogênea e diversificada do setor de serviços, a questão ambiental se apresenta como um desafio, e, nesse sentido, os setores hoteleiro, bancário e hospitalar são os que demonstram os maiores avanços em relação ao levantamento e avaliação dos impactos ambientais (DEMAJOROVIC, 2006).

A escolha do Posto Médico de Esquadra (PAMESQ), localizado na Base Naval do Rio de Janeiro (BNRJ), como unidade de análise, deve-se ao fato de ser a primeira Organização Militar (OM) da Marinha do Brasil (MB) a obter certificação ambiental pela Diretoria de Portos e Costas (DPC), em 2010, após Auditoria Ambiental em suas instalações. Assim, o PAMESQ reúne condições de ser estudado por se mostrar como um caso decisivo, de acordo com Yin (2005), e satisfazer as condições para testar os objetivos propostos.

$\mathrm{O}$ estudo de caso único adotado aqui representa uma maneira de investigar um tópico empírico, pois "o estudo de caso, permite uma investigação para se preservar as características significativas da vida real" (YIN, 2005), por meio de trabalhos explanatórios (causais), exploratório ou descritivo, sendo indicados para os casos em que o foco se encontra em fenômenos contemporâneos inseridos em um contexto real.

Para a realização deste trabalho utilizou-se diversas fontes de evidências, possibilitando o desenvolvimento de linhas convergentes de investigação por meio de um processo de triangulação de informações de fontes de dados (YIN, 2005). Os instrumentos de coletas de dados utilizados foram: documentos, registros em arquivos, entrevistas, observação direta e participativa.

$\mathrm{Na}$ pesquisa documental e nos registros em arquivos foram utilizados o Programa de Gestão Ambiental da BNRJ, os Planos de Gerenciamento de Resíduos de Serviço de Saúde (PGRSS) dos anos de 2008, 2009, 2010 e 2011, Normas Técnicas Ambientais da MB, Ordens Internas e cartazes.

Um roteiro para as entrevistas foi elaborado por meio de informações obtidas na pesquisa bibliográfica. As entrevistas foram compostas por questões relacionadas ao PGRSS visando permitir a caracterização das etapas do gerenciamento de RSS. Participaram das entrevistas os responsáveis diretos pela administração do PGRSS, o gestor do Sistema de Gestão Ambiental (SGA) e auditores ambientais que certificaram o SGA. As perguntas foram previamente enviadas aos entrevistados para que pudessem se preparar ou levantar as informações de que não dispunham.

O conteúdo das perguntas buscou informações sobre o nível de gerenciamento dos RSS na Organização Militar e não o entendimento dos entrevistados, desta forma foram elaborados seguintes questionamentos: se a OM tem conhecimento da RDC $n^{\circ} 306 / 2004$, da ANVISA e da Resolução CONAMA 358/2005; se a OM tem conhecimento de que o gerador dos resíduos é responsável pela sua destinação final; se possui um Programa de Gestão de Resíduos Sólidos dos Serviços de Saúde; se possui militar ou servidor civil qualificado em Gestão de Resíduos Sólidos dos Serviços de Saúde; e se os recipientes que acondicionam e segregam os sacos plásticos são devidamente identificados. Para tratamento e análise 

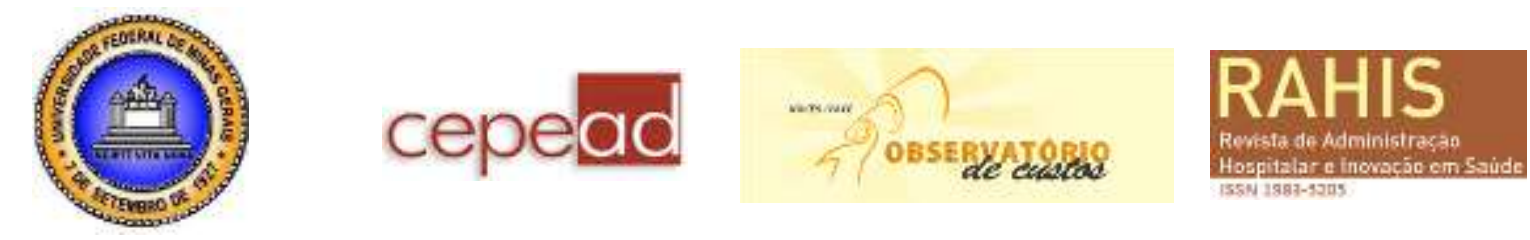

estatística dos dados foi utilizado o programa Statistical Package for Social Science for Windows (SPSS).

As duas maneiras de observação direta (a formal e a informal) foram utilizadas para este estudo de caso. A observação formal contemplou a participação em reuniões pertinentes aos assuntos do SGA e PGRSS. Da maneira informal observou-se a área de armazenamento de resíduos, o manuseio dos resíduos e os setores produtores de resíduos. A observação participante também foi utilizada, pois o autor participou das atividades de auditoria ambiental, na qualidade de consultor ambiental.

Assim, a triangulação foi realizada utilizando os resultados obtidos com as entrevistas, análise de documentos e registros em arquivos, como sugere Yin (2005). As diversas fontes de evidência aumentam a probabilidade de se alcançar uma teoria mais, factível com os dados (EISENHARDT, 1989).

\section{RESULTADOS E DISCUSSÃO}

Neste item estão apresentados os resultados obtidos na pesquisa. Os resultados apresentam uma análise do PGRSS, a classificação e os tipos de resíduos gerados pelo PAMESQ, além das estratégias empregadas para o tratamento dos resíduos pela Organização Militar.

\section{Análise do PGRSS}

O Plano de GRSS do PAMESQ está de acordo com as diretrizes da RDC n 306/2004. Foi implantado em 2004 e tem sido revisado anualmente. Neste trabalho foram analisados os PGRSS de 2008, 2009, 2010 e 2011.

Em relação ao aspecto segregação, os resíduos são separados de acordo com a classificação apresentada na tabela 1. Para a identificação e reconhecimento visual dos recipientes de acondicionamento e armazenamento temporário são utilizadas etiquetas, em consonância com a simbologia citada na RDC $n^{\circ} 306 / 2004$, da ANVISA. A título de exemplificação no mesmo quadro estão apresentas as principais unidades geradoras das diferentes classes.

Conforme relato do Gestor de Resíduos de Saúde do PAMESQ: “... as lixeiras e descarpacks também rotulados com exemplos de lixo considerado infectante (lixeira Branca com saco branco leitoso) e não infectante (lixeira verde com saco preto)".

Tabela 1: Classificação dos Resíduos de Serviço de Saúde (RSS) nos setores do PAMESQ.

\begin{tabular}{c|l|c|c}
\hline GRUPO & \multicolumn{1}{|c|}{ CARACTERISTICAS } & SETORES DO \\
PAMESQ
\end{tabular}




\begin{tabular}{|c|c|c|}
\hline B & $\begin{array}{l}\text { inflamabilidade, corrosividade, reatividade e toxicidade. Nesse grupo, encontram-se } \\
\text { os produtos hormonais, produtos antimicrobianos, imunomoduladores, resíduos e } \\
\text { insumos farmacêuticos dos medicamentos controlados, resíduos de saneantes, } \\
\text { desinfetantes, resíduos contendo metais pesados; reagentes para laboratório, } \\
\text { inclusive os recipientes contaminados por estes. }\end{array}$ & $\begin{array}{l}\text { Ambulatório, } \\
\text { Laboratório, } \\
\text { Farmácia, } \\
\text { Radiologia, } \\
\text { Esterilização e Copa. }\end{array}$ \\
\hline C & $\begin{array}{l}\text { Todo material resultante de atividades humanas que contenham radionuclídeos em } \\
\text { quantidades superiores aos limites de eliminação especificados nas normas da } \\
\text { Comissão Nacional de Energia Nuclear - CNEN e para os quais a reutilização é } \\
\text { imprópria ou não prevista. Fazem parte desse grupo quaisquer materiais resultantes } \\
\text { de laboratórios de análises clínicas, nuclear e radioterapia que contenham } \\
\text { radionuclídeos em quantidade superior aos limites de eliminação. }\end{array}$ & Radiologia \\
\hline D & $\begin{array}{l}\text { Resíduos que não apresentem risco biológico, químico ou radiológico à saúde ou ao } \\
\text { meio ambiente, podendo ser equiparados aos resíduos domiciliares. Enquadram-se } \\
\text { nesse grupo, papel de uso sanitário e fralda, resto alimentar de paciente, material } \\
\text { utilizado em antissepsia, equipo de soro, resíduos provenientes das áreas } \\
\text { administrativas, resíduos de varrição, jardins, resíduos de gesso provenientes de } \\
\text { assistência à saúde. }\end{array}$ & $\begin{array}{c}\text { Emergência, } \\
\text { Odontologia, } \\
\text { Ambulatório, } \\
\text { Laboratório, } \\
\text { Farmácia, } \\
\text { Radiologia, } \\
\text { Esterilização e Copa. }\end{array}$ \\
\hline $\mathbf{E}$ & $\begin{array}{l}\text { Resíduos perfurocortantes ou escarificantes, tais como: agulhas, escalpes, ampolas } \\
\text { de vidro, limas endodônticas, lâminas de bisturi, lancetas; tubos capilares, } \\
\text { micropipetas; lâminas e lamínulas, espátulas, e os utensílios de vidro quebrados no } \\
\text { laboratório. }\end{array}$ & $\begin{array}{l}\text { Emergência, } \\
\text { Odontologia, } \\
\text { Ambulatório, } \\
\text { Laboratório, } \\
\text { Farmácia, Radiologia } \\
\text { e Esterilização. }\end{array}$ \\
\hline
\end{tabular}

Fonte: Elaborada em consonância com a Resolução CONAMA nº 358/2005.

As principais características do gerenciamento de RSS no PAMESQ estão resumidas na tabela 2 e corroboram os resultados de Garcia e Zanetti-Ramos (2004) ao afirmarem que PGRSS deve ser elaborado com base nas características e volume dos resíduos de serviços de saúde gerados, estabelecendo as diretrizes de manejo desses resíduos, incluindo as medidas de: segregação, acondicionamento, identificação, transporte interno, armazenamento intermediário, armazenamento temporário, tratamento, armazenamento externo, coleta e transporte externo e destinação final.

\section{Tabela 2: Principais características do gerenciamento de RSS no PAMESQ.}

\section{GERENCIAMENTO DE RSS NO PAMESQ}

\begin{tabular}{cl}
\hline $\begin{array}{c}\text { Plano de Gerenciamento } \\
\text { de Resíduos do Serviço } \\
\text { de Saúde - PGRSS }\end{array}$ & $\begin{array}{l}\text { - Implantado desde 2004 de acordo com as exigências da legislação do Conselho Nacional } \\
\text { do Meio Ambiente (CONAMA) para serviços de saúde, bem como com a legislação federal } \\
\text { definida pela ANVISA. }\end{array}$ \\
\hline Segregação & $\begin{array}{l}\text { - Os resíduos sólidos são separados em recipiente específico para cada tipo de resíduo, } \\
\text { identificando os resíduos conforme suas características e potencial infectante. }\end{array}$ \\
\hline $\begin{array}{c}\text { Acondicionamento e } \\
\text { Armazenamento }\end{array}$ & $\begin{array}{l}\text { - Os resíduos são armazenados em embalagens de plástico e papel seguindo uma } \\
\text { padronização de cores, conforme o tipo de resíduo sólido, de acordo com a legislação } \\
\text { vigente; e }\end{array}$ \\
$\begin{array}{l}\text { - O Posto possui lixeiras com tampas plásticas resistentes, para o armazenamento dos } \\
\text { resíduos, identificadas devidamente de acordo com o tipo de resíduo. }\end{array}$ \\
$\begin{array}{c}\text { - Os resíduos são recolhidos dos recipientes de armazenamento por profissionais qualificados } \\
\text { e colocados em local de armazenamento temporário; e } \\
\text { - Cada tipo de resíduo (biológico, orgânico ou químico) é recolhido em recipientes } \\
\text { específicos, identificados através de cores diferentes. }\end{array}$ \\
\hline
\end{tabular}




\begin{tabular}{|c|c|}
\hline Armazenamento Final & $\begin{array}{l}\text { - Os resíduos são armazenados em um depósito de armazenamento externo para seu posterior } \\
\text { destino final. Este local está localizado na área externa ao Posto e é de fácil acesso aos } \\
\text { funcionários da empresa de coleta, o mesmo é construído em alvenaria, com porta e janelas } \\
\text { para circulação do ar. Além disso, possui revestimento interno (piso e paredes até o teto) } \\
\text { com material lavável (cerâmica e azulejos). }\end{array}$ \\
\hline $\begin{array}{c}\text { Tratamento e destino } \\
\text { final }\end{array}$ & $\begin{array}{l}\text { - Os resíduos orgânicos são recolhidos por empresa especializada e credenciada pelo Órgão } \\
\text { Ambiental para posterior depósito em aterro sanitário; } \\
\text { - Os resíduos infectantes (biológicos e químicos) são recolhidos e autoclavados e incinerados } \\
\text { por empresa especializada; e } \\
\text { - Os resíduos secos recicláveis, como papel e embalagens plásticas, são destinados aos } \\
\text { contêineres para material reciclável. }\end{array}$ \\
\hline
\end{tabular}

Desta forma, o PGRSS do PAMESQ visa minimizar a produção de resíduos, tratá-los e encaminhá-los de forma segura ao destino final e deste modo prevenir e controlar riscos ocupacionais, à saúde pública e ao meio ambiente. Apesar de ter implementado o PGRSS desde 2004, apenas foram disponibilizados para este estudo dados de 2008 a 2011.

\section{Análise dos Resíduos gerados pelo PAMESQ}

Todos os resíduos sólidos gerados pelo PAMESQ são quantificados em litros e os dados consolidados em planilhas de controle mensal que constam como anexo dos PGRSS. Os dados referentes aos anos de 2008, 2009, 2010 e 2011 são apresentados na tabela 3.

De acordo com os dados da Tabela 3 houve uma redução na geração de resíduos no período de 2008 a 2010 e um aumento em 2011. O aumento para geração de resíduos no ano de 2011 pode está relacionada ao aumento no número de pacientes para vacinação contra Hepatite e Febre Amarela que passaram a ser obrigatórias para todos os militares. Os baixos valores observados nos meses de abril a junho de 2010 podem ser justificados pela ausência dos navios da Esquadra para operações militares, e consequentemente uma redução significativa no número de procedimentos realizados pelos PAMESQ.

Tabela 3: Quantidades mensais de Resíduos produzidos pelo PAMESQ no período de 2008 até 2011.

\begin{tabular}{|c|c|c|c|c|c|}
\hline Mês / Ano & 2008 & 2009 & 2010 & 2011 & TOTAL (L) \\
\hline Janeiro & 810 & 621 & 900 & 889 & 3.220 \\
\hline Fevereiro & 1.625 & 729 & 619 & 849 & 3.822 \\
\hline Março & 719 & 813 & 1.269 & 1.085 & 3.886 \\
\hline Abril & 1.200 & 851 & 40 & 1.261 & 3.352 \\
\hline Maio & 545 & 910 & 164 & 1.110 & 2.729 \\
\hline Junho & 843 & 796 & 224 & 941 & 2.804 \\
\hline Julho & 376 & 760 & 211 & 998 & 2.345 \\
\hline Agosto & 769 & 731 & 863 & 1.063 & 3.426 \\
\hline Setembro & 1.050 & 907 & 1.114 & 1.331 & 4.402 \\
\hline Outubro & 810 & 800 & 837 & 850 & 3.297 \\
\hline \begin{tabular}{|l|} 
Novembro \\
\end{tabular} & 893 & 550 & 970 & 849 & 3.262 \\
\hline Dezembro & 515 & 897 & 1.220 & 1.092 & 3.724 \\
\hline TOTAL & 10.155 & 9.365 & 8.431 & 12.318 & 40.269 \\
\hline
\end{tabular}

Fonte: Autores

Para análise estatística dos dados foram empregados os teste de Shapiro-Wilk para verificar a normalidade da amostra, teste homoscedasticidade para testar a homogeneidade da amostra, testes de Kruskal-Wallis e de Dunn para verificar se há diferenças entre as amostras. 

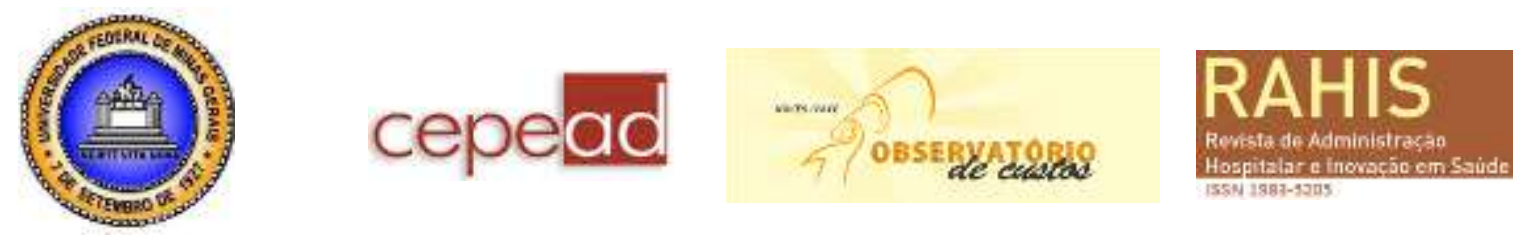

As amostras são compostas pelas quantidades de resíduos gerados no PAMESQ, não havendo registro dentro do PGRSS por setor. Os testes estatísticos foram realizados para saber se há diferenças expressivas entre os totais e se são significativas.

A análise estatística por intermédio do teste de Shapiro-Wilk mostrou que todas as amostras (anos) são aderentes à distribuição normal. Porém, o teste de homoscedasticidade de Levene mostrou-se significante $(\mathrm{p}<0,05)$, indicando que as amostras não têm variâncias homogêneas. Desta forma a opção foi usar um teste não paramétrico.

O teste de Kruskal-Wallis mostrou-se significante $(\mathrm{p}=0,0257)$, indicando que há diferenças entre as amostras. E o teste de Dunn indicou que apenas as amostras 2 (2009) e 4 (2011) são diferentes, sendo todas as outras combinações estatisticamente semelhantes, conforme os dados apresentados na figura 1.

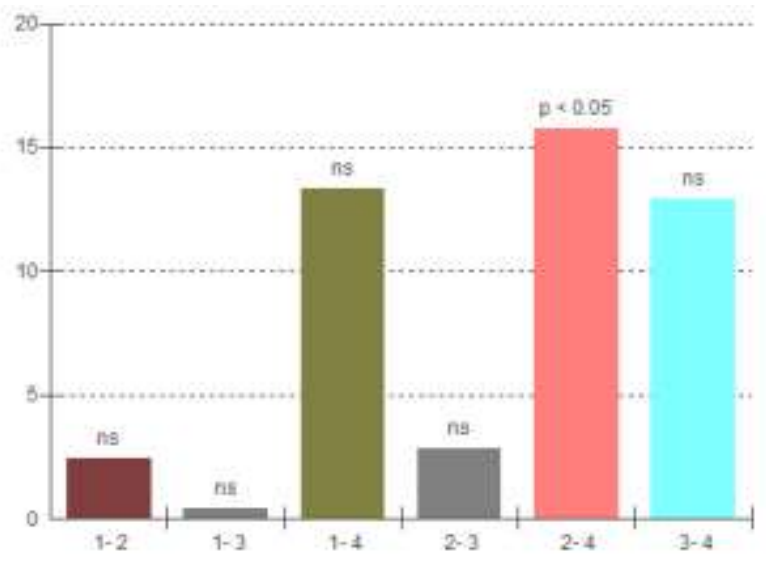

Figura 1: Diferenças entre as amostras de acordo com o Teste Kruskal-Wallis.

Registra-se que não foi possível estabelecer correlação entre a quantidade de resíduos por paciente atendido e, portanto a impossibilidade de apresentar um indicador de ecoeficiência. Mas, pela intensificação do treinamento é possível inferir que o decréscimo na produção de resíduos pode ser uma explicação para a eficiência no processo de manuseio e destinação do material. Tal perspectiva não apresenta correlação com o estudo realizado por Taghipour e Mosaferi (2009a), mas corrobora a análise realizada por Schneider (2004) ao apontar que a educação continuada contribui para reduzir a geração de resíduos infectantes.

A partir dos dados da tabela 3 e das informações constantes nos PGRSS foi possível classificar e estimar o percentual de resíduos gerados por setor, de acordo com as informações consolidadas nas tabelas 4 e 5 .

Tabela 4: Identificação de resíduos gerados pelos setores do PAMESQ.

\begin{tabular}{|c|c|c|c|}
\hline \multirow[t]{2}{*}{ 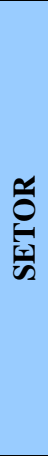 } & Emergência & \multirow[t]{2}{*}{ 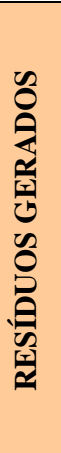 } & $\begin{array}{l}\text { Agulhas descartáveis, Frasco, perfusor e equipo de soro, Gaze, algodão, compressa, Equipo } \\
\text { de soro e perfusor sujo de sangue, Seringa descartável para aspiração de medicação, Agulha } \\
\text { para aspiração de medicação, Seringa com agulha conectada, Papel toalha, Embalagem de } \\
\text { seringa, agulha e outras, Copo descartável, Luva descartável, Frasco de antimicrobiano } \\
\text { parcialmente utilizado, Frasco vazio de álcool, Fita adesiva, Protetor facial, Avental, gorro e } \\
\text { máscara descartáveis, Restos de alimentos e embalagens, Papel administrativo, formulários e } \\
\text { rascunhos, Drenos, sonda vesical com líquidos corpóreos, Coletor de urina, Coletor de urina } \\
\text { com líquido corpóreo, Hipoclorito de sódio, Cateter venoso periférico, Drenos, Sonda vesical/ } \\
\text { enteral/ nasogástrica, Ampola de vidro ou outro material perfurocortante, Papel sanitário, } \\
\text { absorvente higiênico, fralda descartável e Material contendo sangue ou líquido corpóreo na } \\
\text { forma livre. }\end{array}$ \\
\hline & Odontologia & & Agulhas descartáveis, Frasco, perfusor e equipo de soro, Equipo de soro e perfusor sujo de \\
\hline
\end{tabular}



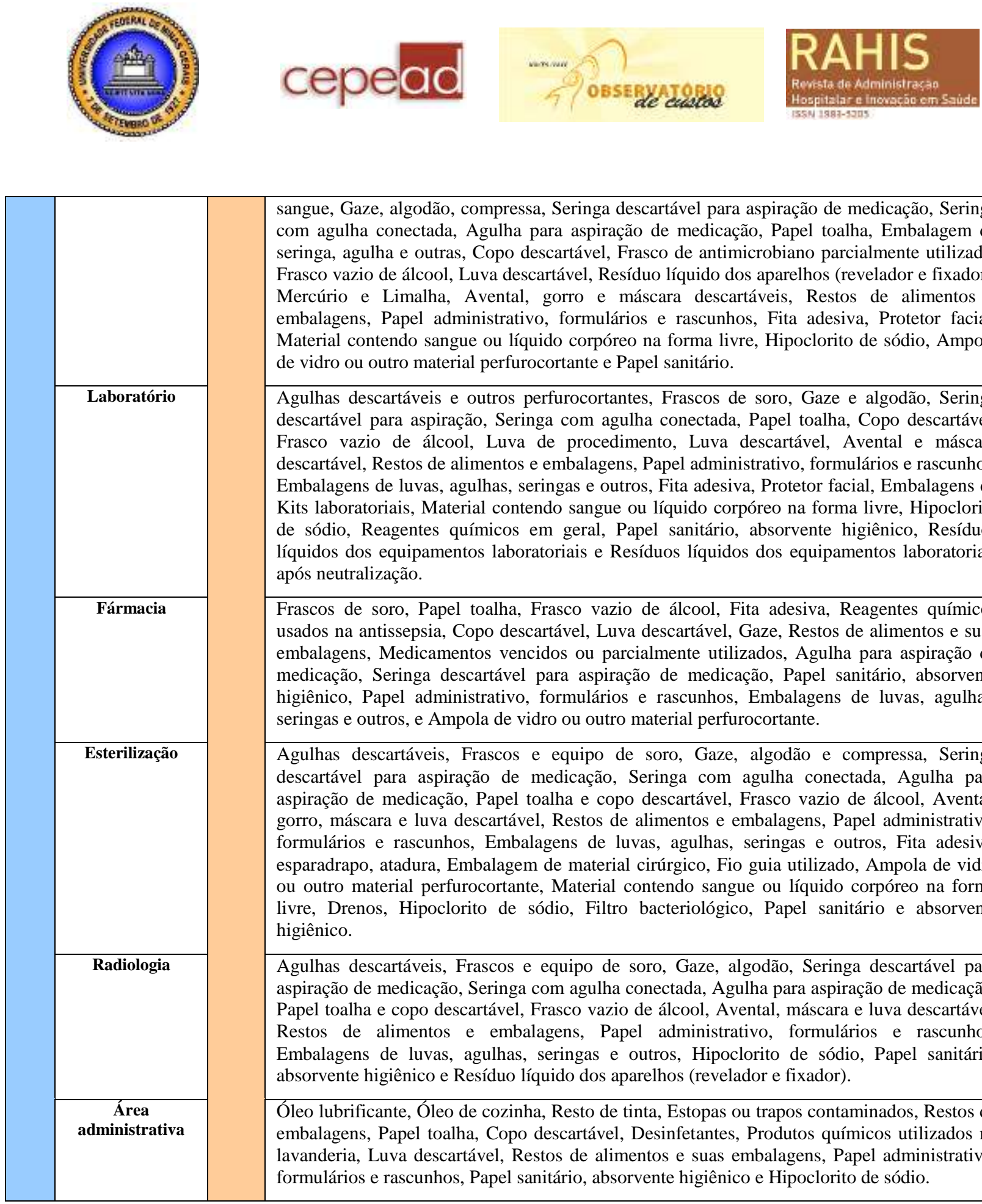

sangue, Gaze, algodão, compressa, Seringa descartável para aspiração de medicação, Seringa com agulha conectada, Agulha para aspiração de medicação, Papel toalha, Embalagem de seringa, agulha e outras, Copo descartável, Frasco de antimicrobiano parcialmente utilizado, Frasco vazio de álcool, Luva descartável, Resíduo líquido dos aparelhos (revelador e fixador), Mercúrio e Limalha, Avental, gorro e máscara descartáveis, Restos de alimentos e embalagens, Papel administrativo, formulários e rascunhos, Fita adesiva, Protetor facial, Material contendo sangue ou líquido corpóreo na forma livre, Hipoclorito de sódio, Ampola de vidro ou outro material perfurocortante e Papel sanitário.

Agulhas descartáveis e outros perfurocortantes, Frascos de soro, Gaze e algodão, Seringa descartável para aspiração, Seringa com agulha conectada, Papel toalha, Copo descartável, Frasco vazio de álcool, Luva de procedimento, Luva descartável, Avental e máscara descartável, Restos de alimentos e embalagens, Papel administrativo, formulários e rascunhos, Embalagens de luvas, agulhas, seringas e outros, Fita adesiva, Protetor facial, Embalagens de Kits laboratoriais, Material contendo sangue ou líquido corpóreo na forma livre, Hipoclorito de sódio, Reagentes químicos em geral, Papel sanitário, absorvente higiênico, Resíduos líquidos dos equipamentos laboratoriais e Resíduos líquidos dos equipamentos laboratoriais após neutralização.

Frascos de soro, Papel toalha, Frasco vazio de álcool, Fita adesiva, Reagentes químicos usados na antissepsia, Copo descartável, Luva descartável, Gaze, Restos de alimentos e suas embalagens, Medicamentos vencidos ou parcialmente utilizados, Agulha para aspiração de medicação, Seringa descartável para aspiração de medicação, Papel sanitário, absorvente higiênico, Papel administrativo, formulários e rascunhos, Embalagens de luvas, agulhas, seringas e outros, e Ampola de vidro ou outro material perfurocortante.

Agulhas descartáveis, Frascos e equipo de soro, Gaze, algodão e compressa, Seringa descartável para aspiração de medicação, Seringa com agulha conectada, Agulha para aspiração de medicação, Papel toalha e copo descartável, Frasco vazio de álcool, Avental, gorro, máscara e luva descartável, Restos de alimentos e embalagens, Papel administrativo, formulários e rascunhos, Embalagens de luvas, agulhas, seringas e outros, Fita adesiva, esparadrapo, atadura, Embalagem de material cirúrgico, Fio guia utilizado, Ampola de vidro ou outro material perfurocortante, Material contendo sangue ou líquido corpóreo na forma livre, Drenos, Hipoclorito de sódio, Filtro bacteriológico, Papel sanitário e absorvente higiênico.

Agulhas descartáveis, Frascos e equipo de soro, Gaze, algodão, Seringa descartável para aspiração de medicação, Seringa com agulha conectada, Agulha para aspiração de medicação, Papel toalha e copo descartável, Frasco vazio de álcool, Avental, máscara e luva descartável, Restos de alimentos e embalagens, Papel administrativo, formulários e rascunhos, Embalagens de luvas, agulhas, seringas e outros, Hipoclorito de sódio, Papel sanitário, absorvente higiênico e Resíduo líquido dos aparelhos (revelador e fixador).

Óleo lubrificante, Óleo de cozinha, Resto de tinta, Estopas ou trapos contaminados, Restos de embalagens, Papel toalha, Copo descartável, Desinfetantes, Produtos químicos utilizados na lavanderia, Luva descartável, Restos de alimentos e suas embalagens, Papel administrativo, formulários e rascunhos, Papel sanitário, absorvente higiênico e Hipoclorito de sódio.

Fonte: Autores.

A tabela 4 apresenta a listagem dos resíduos gerados pelos setores do PAMESQ. A presença de materiais plásticos e papel em todos os setores é um indicador positivo para o fortalecimento da coleta seletiva de resíduos. Os dados apresentam semelhança em relação a composição gravimétrica observada por Viriato e Moura (2011) e com a composição apontada no estudo de Abd El-Salam (2010). A emergência, o laboratório e a odontologia geram resíduos similares, bem como a radiologia com os resíduos da farmácia. $\mathrm{Na}$ área administrativa a presença de resíduos com características domésticas é caracterizada por óleo de cozinha, plásticos, papel e restos de alimentos.

$\mathrm{Na}$ tabela 5 são apresentados os percentuais dos resíduos gerados no PAMESQ por setor. Os resíduos do grupo A são gerados apenas nos setores médico-odontológico, laboratorial e de esterilização. Em relação aos resíduos do grupo $\mathrm{C}$ não há registro de sua 
produção, pois são recolhidos por pessoal especializado para outra unidade de saúde que centraliza o recolhimento dos resíduos de todas as Organizações de Saúde dos municípios do Rio de Janeiro e Niterói.

Os resíduos dos grupos $\mathrm{B}$ e $\mathrm{D}$ são produzidos por todos os setores, sendo predominante a produção para o grupo D com percentual superior a 53\% em todos os setores. Para o grupo E há registro de produção para todos os setores com atividades médica e odontológica, exceto para as áreas administrativas.

Tabela 5: Distribuição percentual dos Resíduos gerados no PAMESQ por setor.

\begin{tabular}{|c|c|c|c|c|c|}
\hline SETOR & GRUPO A & GRUPO B & GRUPO C & GRUPO D & GRUPO E \\
\hline Emergência & $14 \%$ & $7 \%$ & - & $61 \%$ & $18 \%$ \\
\hline Odontologia & $13,4 \%$ & $13,4 \%$ & - & $56,6 \%$ & $16,6 \%$ \\
\hline Ambulatório & $14 \%$ & $7 \%$ & - & $61 \%$ & $18 \%$ \\
\hline Laboratório & $4 \%$ & $13 \%$ & - & $74 \%$ & $9 \%$ \\
\hline Farmácia & - & $12,5 \%$ & - & $75 \%$ & $12,5 \%$ \\
\hline Esterilização & $9,3 \%$ & $4,7 \%$ & - & $62 \%$ & $24 \%$ \\
\hline Radiologia & - & $13 \%$ & - & $67 \%$ & $20 \%$ \\
\hline Copa & - & $46 \%$ & - & $54 \%$ & - \\
\hline Área de Circulação & - & $20 \%$ & - & $80 \%$ & - \\
\hline
\end{tabular}

Em relação aos resíduos do grupo $\mathrm{D}$ e em consonância com as informações disponíveis nos PGRSS foi possível estimar o percentual de material plástico, papel, vidros e sobras de alimentos, conforme ilustrado na figura 2.

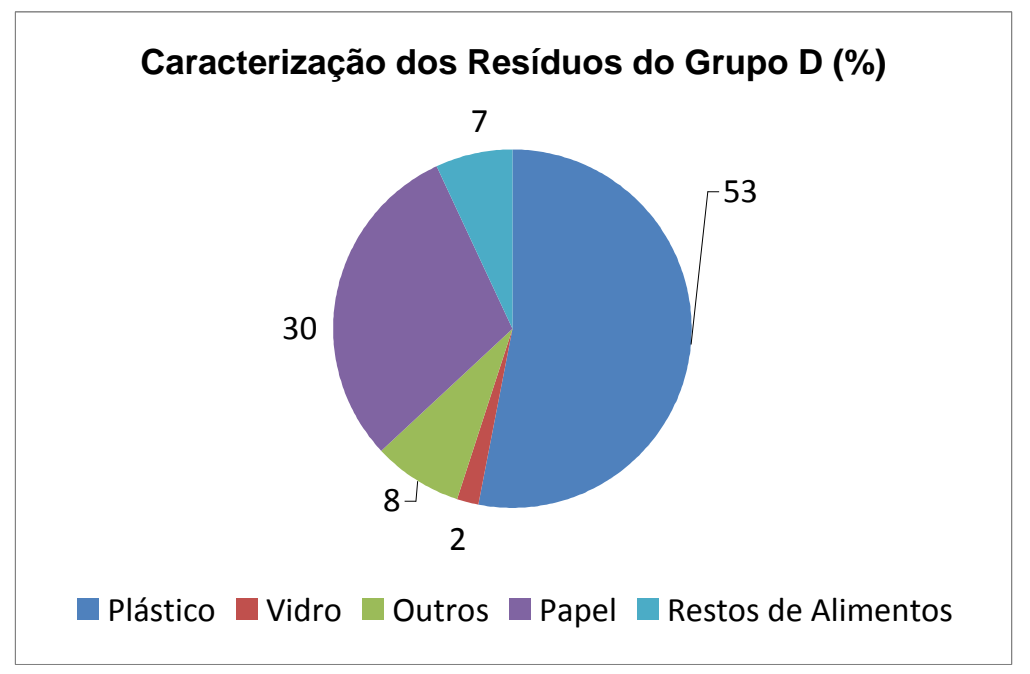

Figura 2: Caracterização dos Resíduos do Grupo D gerados pelo PAMESQ. Fonte: Autores.

Tais informações corroboram estudos realizados por Abd El-Salam (2010) e Taghipour e Mosaferi (2009b), segundo os quais aproximadamente $70 \%$ dos resíduos 

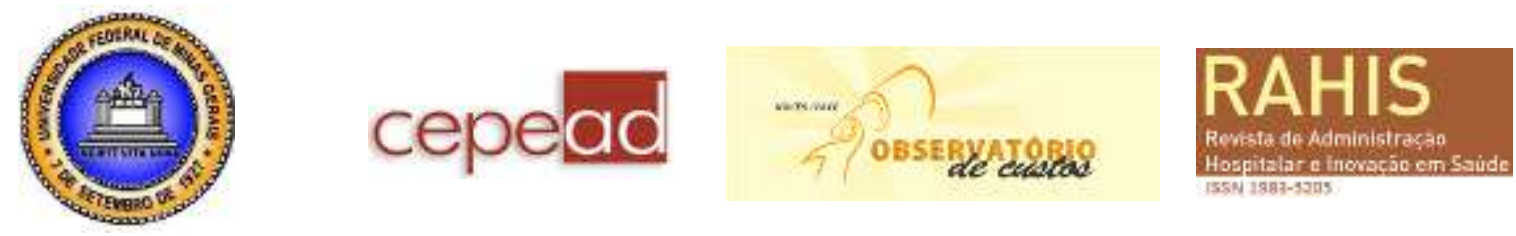

produzidos pelas instituições de saúde são considerados resíduos domésticos, enquanto 30\% dos resíduos são considerados infecciosos.

\section{Tratamento dos resíduos}

O tratamento consiste na aplicação de método, técnica ou processo que modifique as características dos riscos inerentes aos resíduos, reduzindo ou eliminando o risco de contaminação, de acidentes ocupacionais ou de danos ao meio ambiente. No PAMESQ não é realizado o tratamento dos resíduos gerados, apenas o armazenamento para tratamento externo, de acordo com os dados registrados na tabela 6.

Tabela 6: Tratamento e destinação dos resíduos gerados pelo PAMESQ.

\begin{tabular}{|c|c|c|c|c|}
\hline $\begin{array}{c}\text { GRUPO DE } \\
\text { RESÍDUO }\end{array}$ & SETOR & $\begin{array}{c}\text { TRATAMENTO } \\
\text { INTERNO }\end{array}$ & $\begin{array}{c}\text { TRATAMENTO } \\
\text { EXTERNO }\end{array}$ & EMPRESA \\
\hline A & $\begin{array}{c}\text { Emergência } \\
\text { Odontologia } \\
\text { Laboratório }\end{array}$ & $\begin{array}{c}\text { Armazenamento } \\
\text { Temporário }\end{array}$ & $\begin{array}{c}\text { A + I } \\
\text { Rodoviários }\end{array}$ \\
\hline B & $\begin{array}{c}\text { Odontologia } \\
\text { Laboratório } \\
\text { Radiologia }\end{array}$ & $\begin{array}{c}\text { Armazenamento } \\
\text { Temporário }\end{array}$ & $\begin{array}{c}\text { N + R } \\
\text { N/A }\end{array}$ & NOMOS Análises Minerais \\
\hline C & PAMESQ & $\begin{array}{c}\text { Armazenamento } \\
\text { Temporário }\end{array}$ & $\begin{array}{c}\text { Aterro Sanitário/ } \\
\text { Coleta seletiva }\end{array}$ & EcoCare Ambiental \\
\hline D & $\begin{array}{c}\text { Emergência } \\
\text { Odontologia } \\
\text { Laboratório }\end{array}$ & $\begin{array}{c}\text { Armazenamento } \\
\text { temporário }\end{array}$ & I + A & $\begin{array}{c}\text { 2MC Transportes } \\
\text { Rodoviários }\end{array}$ \\
\hline
\end{tabular}

Legenda: A = Autoclave; N = Neutralização química; I = Incineração; R = Recuperação de metais; e N/A = Não se aplica. Fonte: Autores.

O tratamento externo dos resíduos do PAMESQ é feito pela 2MC Transportes Rodoviários e pela empresa de Resíduo ALL, cuja destinação final de todos os resíduos do grupo A e E é a incineração e deposição em aterro sanitário, conforme registros da tabela 6. Os resíduos do grupo B utilizados no laboratório, quando necessário são neutralizados antes do descarte na rede coletora de esgoto, os gerados no serviço de radiologia e odontologia são recolhidos e enviados a empresa recuperadora de metais licenciada.

O tratamento de resíduos realizado pelo PAMESQ não corrobora os estudos realizados por Abd El-Salam (2010) e Uysal \& Tinmaz (2004), pois se constatou que a segregação dos resíduos obedece a procedimentos estabelecidos pelos requisitos legais e não são descartados como resíduos domésticos. Observa-se, ainda, que os resíduos líquidos são encaminhados para o sistema municipal de esgoto após tratamento prévio, esses resultados vão de encontro com a pesquisa realizada por Abdulla et al. (2008).

\section{CONSIDERAÇÕES FINAIS}

O objetivo desta pesquisa foi analisar a gestão de resíduos de serviços de saúde em uma Organização Militar da Marinha do Brasil. Os resultados mostram que a gestão de resíduos sólidos na área de saúde está sendo aplicada no Posto Médico da Esquadra. O Plano 

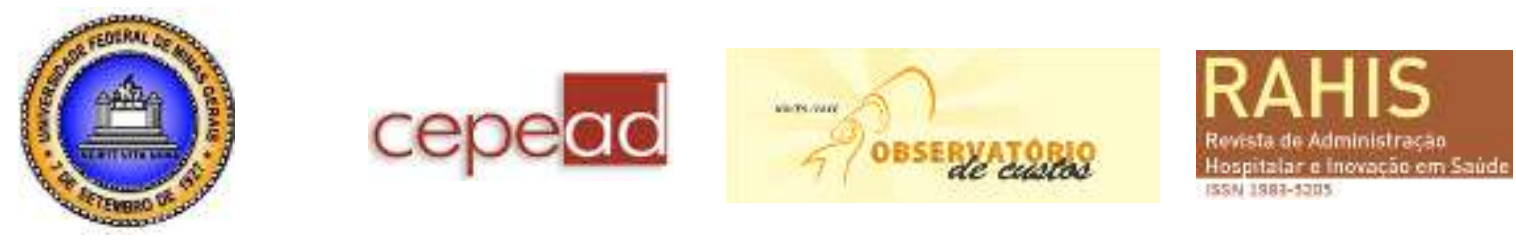

de Gerenciamento de Resíduos implantado na Organização militar evita problemas ambientais e atende as exigências legais, pois gera aumento no tempo de vida útil dos aterros sanitários, em função da correta separação e destinação final dos resíduos gerados, bem como benefícios ambientais à sociedade.

Registra-se que apesar de não ter encontrado dados sobre coleta seletiva de material reciclável, a Organização Militar possui coletores para papéis, plásticos, metais e vidro. Tal iniciativa está registrada no Plano de Gerenciamento de Resíduos, o que mostra uma preocupação com a destinação correta dos resíduos gerados no PAMESQ. Os resultados obtidos na pesquisa apontam que o PGRSS está institucionalizado e integrado aos demais setores da Organização Militar.

Há limitações no estudo que envolvem questões inerentes à cultura militar e que até certo ponto dificulta a obtenção de dados. Sugere-se a continuidade da pesquisa ampliando para um estudo de casos múltiplos com Organizações de Saúde da Marinha, de forma a verificar se a cultura influencia na gestão dos resíduos. Além disso, um comparativo entre as Organizações Militares e outras organizações de saúde pública poderá mostrar se há uma gestão de excelência em relação ao tratamento dos resíduos de saúde no setor público ou se essa excelência está restrita à Marinha

Esse estudo exploratório serviu para o desenvolvimento de alguns indicadores de RSS, que podem contribuir para o desenvolvimento de futuras pesquisas quantitativas com o objetivo de mapear a Gestão de resíduos sólidos de saúde no Brasil. Esse aprofundamento sobre o tema em outros estudos pode identificar pontos comuns e a proposição de uma agenda de pesquisa para o desenvolvimento de um modelo teórico sobre a GRSS em países em desenvolvimento.

\section{REFERÊNCIAS}

ABD EL-SALAM, M. M. Hospital waste management in El-Beheira Governorate, Egypt. Journal of Environmental Management, v.91, n.3, p. 618-629, 2010.

ABDULLA, F.; ABU QDAIS, H.; RABI, A. Site investigation on medical waste management practices in northern Jordan. Waste Management, v.28, n.2, p. 450-458, 2008.

ALI, M.; KUROIWA, C. Status and challenges of hospital solid waste management: case studies from Thailand, Pakistan, and Mongolia. Journal of Material Cycles and Waste Management, v.11 p. 251-257, 2009.

ANANTH, A. P.; PRASHANTHINI, V.; VISVANATHAN, C. Healthcare waste management in Asia. Waste Management, v.30, n.1, p.154-161, 2010.

BARBIERI, J. C. Gestão Ambiental empresarial: conceitos, modelos e instrumentos. 2 ed. São Paulo: Saraiva, 2007.

BRASIL. Resolução CONAMA No. 05/1993. Define as normas mínimas para tratamento de resíduos sólidos oriundos de serviços de saúde, portos e aeroportos e terminais rodoviários. Diário Oficial da União, 31 ago., Seção 1. Brasília; 2001. 

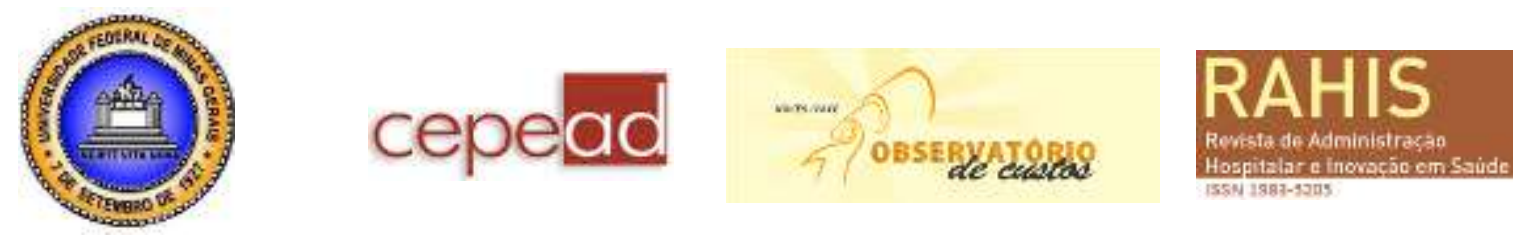

BRASIL. Resolução RDC n ${ }^{\circ}$ 306/2004. Disposição sobre o regulamento técnico para o gerenciamento de resíduos de serviços de saúde. Diretoria Colegiada da Agência Nacional de Vigilância Sanitária - ANVISA. Diário Oficial da União, 10 dez., Seção 1. Brasília; 2004.

BRASIL. Resolução CONAMA No. 358/2005. Dispõe sobre o tratamento e a destinação final dos resíduos dos serviços de saúde. Diário Oficial da União, 01 out., Seção 1. Brasília; 2005.

BRASIL. Lei No. 12.305 de agosto de 2010. Institui a Política Nacional de Resíduos Sólidos. Diário Oficial da União, 3 ago., Seção 1. Brasília; 2010.

CALEGARI, L.; GODOY, L. P.; SILVEIRA, D. D. Sistema de gerenciamento ambiental (SGA): uma contribuição para a melhoria dos serviços de saúde hospitalar e atendimento à legislação ambiental. Anais do XII SIMPEP - Bauru, SP, 2005.

CAMARGO, M. E.; MOTTA, M. E. V.; LUNELlI, M. O.; SEVERO, E. A. Resíduos Sólidos de Serviço de Saúde: Um Estudo Sobre o Gerenciamento. Scientia Plena, vol.5, no. 7, 2009.

CASTRO, J. M. A. Resíduos Perigosos no Direito Ambiental Internacional. Porto Alegre: Formato Artes Gráficas, 2003, p.52.

CORRÊA, A. F. Gerenciamento dos resíduos sólidos dos serviços de saúde - aspectos gerais e análise dos processos de gerenciamento pelas Organizações Militares de Saúde do Exército Brasileiro. 2003.20 Disponível http://www.bvsde.paho.org/bvsacd/cd51/exercito.pdf. Acesso em: 27 ago. 2012.

DEMAJOROVIC, J. Ecoeficiência em serviços: diminuindo impactos e aprimorando benefícios ambientais. In: VILELA JR, A; DEMAJOROVIC, J. (Org.). Modelos e Ferramentas de Gestão Ambiental: Desafios e Perspectivas para as Organizações. São Paulo: Editora SENAC, 2006.

EISENHARDT, K.M. Building Theories from case study research. Academy of Management Review. Califórnia, v. 14, n. 4, p. 532-550, 1989.

FERREIRA, J. A. Solid Waste and Nosocomial Waste: An Ethical Discussion. Caderno de Saúde Pública, Rio de Janeiro, 11 (2): 314-320, 1995.

GARCIA, L. P.; ZANETTI-RAMOS, B. G. Gerenciamento dos resíduos de serviços de saúde: uma questão de biossegurança. Caderno de Saúde Pública, Rio de Janeiro, 20(3):744-752, 2004.

HOSSAIN, M. S.; SANTHANAM, A.; NIK NORULAINI, N. A.; OMAR, A. K. Clinical solid waste management practices and its impact on human health and environment - A review. Waste Management, v.31, n.4, p. 754-766, 2011.

MACEDO, L. C.; LAROCCA, L. M.; CHAVES, M. M. N.; PERNA, P. O.; MUNTSCH, S. M. A.; DAMACENO, E. F. C.; SOUZA, T. S.; POLIGUESI, C. B.; TRUPPEL, T. C.; SOUZA, C. Segregação de resíduos nos serviços de saúde: a Educação Ambiental em um Hospital-Escola. Cogitare Enfermagem. Abr/Jun; v.12, n.2, p. 183-188, 2007. 

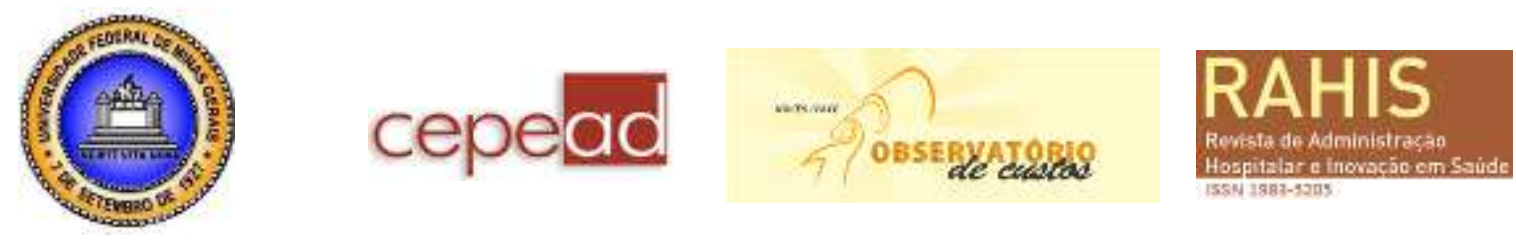

MOHAMED, L. F.; EBRAHIM, S. A.; AL-THUKAIR, A. A. Hazardous healthcare waste management in the Kingdom of Bahrain. Waste Management, v.29, n.8, p. 2404-2409, 2009.

NDIDI, N.; NELSON, O.; PATRICIA, O.; SUNDAY, J. Waste management in healthcare establishments within Jos Metropolis, Nigeria. African Journal of Environmental Science and Technology, v. 3, n.12, p. 459-465, 2009.

SCHNEIDER, V. E. Sistemas de gerenciamento de resíduos sólidos de serviços de saúde: contribuição ao estudo das variáveis que interferem no processo de implantação, monitoramento e custos decorrentes. Tese de Doutorado. Departamento de Engenharia de Recursos Hídricos e Saneamento, Porto Alegre: IPH/UFRGS, 2004.

SILVA, C. E. ; HOPPE, A. E. Diagnóstico dos Resíduos de Serviços de Saúde no interior do Rio Grande do Sul. Revista de Engenharia Sanitária Ambiental, v.10, n. 2, p.146-151, 2005.

SISINNO, C. L. S.; BARROS, R. L. P. Ecoeficiência em Laboratórios e Estabelecimentos de Saúde. Bionotícias, n.66, p.8-9, 2004.

SISINNO, C. L. S.; MOREIRA, J.C. Ecoeficiência: um instrumento para a redução da geração de resíduos e desperdícios em estabelecimentos de saúde. Cadernos de Saúde Pública, v.21, n.6, p.1893-1900, 2005.

SISINNO, C. L. S.; RIZZO, A. C. L.; SANTOS, R. L. C. Ecoeficiência aplicada à redução da geração de resíduos sólidos. Rio de Janeiro: CETEM/MCT, 2011.

TAGHIPOUR, H.; MOSAFERI, M. The challenge of medical waste management: a case study in northwest Iran-Tabriz. Waste Management \& Research, v. 27, n.4, p.328-335, 2009a.

TAGHIPOUR, H.; MOSAFERI, M. Characterization of medical waste from hospitals in Tabriz, Iran. Sci Total Environ, v.15 n.5, p. 1527-1535, 2009 b.

TCHOBANOGLOUS, G.; THEISEN, H.; VIGIL, S. Integrated solid waste management: engineering principles and management issues. New York: McGraw Hill, 1993.

UYSAL, F.; TINMAZ, E. Medical waste management in Trachea region of Turkey: suggested remedial action. Waste Management \& Research, v.22, n.5, p. 403-407, 2004.

VELLANI, C. L.; RIBEIRO, M. S. Sistema Contábil para gestão da ecoeficiência empresarial. Revista Contabilidade \& Finanças, v. 20, n. 49, p. 25-43, 2009.

VIRIATO, A.; MOURA, A. Ecoeficiência e economia com a redução dos resíduos infectantes do Hospital Auxiliar de Suzano. O Mundo da Saúde, v.35 n.5, p.305-310, 2011.

YIN, R. K. Estudo de caso: planejamento e métodos. 2a edição, Porto Alegre: Bookmam, 2005. 


\section{cepead}

